Analytical Methods

\title{
Lipophilic phytochemicals from banana fruits of several Musa species
}

\author{
Carla Vilela a $^{\text {, Sónia A.O. Santos }}{ }^{\mathrm{a}}$, Juan J. Villaverde ${ }^{\mathrm{a}, \mathrm{b}}$, Lúcia Oliveira ${ }^{\mathrm{c}, 1}$, Alberto Nunes ${ }^{\mathrm{d}}$, \\ Nereida Cordeiro ${ }^{\mathrm{d}}$, Carmen S.R. Freire ${ }^{\mathrm{a}}$, Armando J.D. Silvestre ${ }^{\mathrm{a}, *}$ \\ ${ }^{a}$ CICECO and Department of Chemistry, University of Aveiro, 3810-193 Aveiro, Portugal \\ ${ }^{\mathrm{b}}$ On leave to DTEVPF - Plant Protection Products Unit, INIA, Ctra. de La Coruña, Km. 7.5, 28040 Madrid, Spain \\ ${ }^{\mathrm{c}}$ Regional Laboratory of Veterinary and Food Safety, Regional Directorate of Agriculture and Rural Development, 9000-254 Funchal, Portugal \\ ${ }^{\mathrm{d}}$ Centre of Exact Science and Engineering, University of Madeira, 9000-390 Funchal, Portugal
}

\section{A R T I C L E I N F O}

\section{Article history:}

Received 9 April 2013

Received in revised form 28 November 2013

Accepted 13 April 2014

Available online 24 April 2014

\section{Keywords:}

Musa acuminata

Musa balbisiana

Hybrids

Ripe banana pulp

GC-MS

Lipophilic extractives

Fatty acids

Sterols

Tocopherol

\begin{abstract}
A B S T R A C T
The chemical composition of the lipophilic extract of ripe pulp of banana fruit from several banana cultivars belonging to the Musa acuminata and Musa balbisiana species (namely 'Chinese Cavendish', 'Giant Cavendish', 'Dwarf Red', 'Grand Nain', 'Eilon', 'Gruesa', 'Silver', 'Ricasa', 'Williams' and 'Zelig') was studied by gas chromatography-mass spectrometry for the first time. The banana cultivars showed similar amounts of lipophilic extractives (ca. $0.4 \%$ of dry material weight) as well as qualitative chemical compositions. The major groups of compounds identified in these fractions were fatty acids and sterols making up $68.6-84.3 \%$ and $11.1-28.0 \%$, respectively, of the total amount of lipophilic components. Smaller amounts of long chain aliphatic alcohols and $\alpha$-tocopherol were also identified. These results are a relevant contribution for the valorisation of these banana cultivars as sources of valuable phytochemicals ( $\omega$ 3 and $\omega-6$ fatty acids, and sterols) with well-established beneficial nutritional and health effects.
\end{abstract}

(c) 2014 Elsevier Ltd. All rights reserved.

\section{Introduction}

Musa is a plant genus from the family Musaceae and order Zingiberales (Arvanitoyannis \& Mavromatis, 2009) that produces the fourth most important food crop in the world after rice, wheat and maize, i.e. bananas and plantains (Sharrock \& Frison, 1998). Although the genus Musa is composed of four taxonomic sections, namely Australimusa, Callimusa, Musa (formerly known as Eumusa) and Rhodochlam, most cultivated varieties (cultivars) originate from intra- and inter-specific hybridisations between two diploid wild species of the section Musa: Musa acuminata (A genome) and Musa balbisiana (B genome) (Lim, 2012). The most important banana cultivars are triploid $A A A$ and plantains are mostly $A A B$, ABB or BBB (Ball, Vrydaghs, Van Den Hauwe, Manwaring, \& De Langhe, 2006). Due to the difficulty of breeding infertile plants, only a few cultivars have been introduced in the last 50 years. However, the advent of clonal propagation, combined with selection programs, led to the singling out of "elite" clones in terms of yield and fruit quality, adapted to the agro-ecological conditions.

\footnotetext{
* Corresponding author. Tel.: +351 234370711.

E-mail address: armsil@ua.pt (A.J.D. Silvestre).

${ }^{1}$ In memory of Lúcia Oliveira who passed away last in April 2013.
}

'Dwarf Cavendish', 'Giant Cavendish' and ‘Gros Michael' are among the most important banana cultivars for fresh consumption (Po \& Po, 2012).

Banana and plantain plants are cultivated in more than 130 countries throughout the tropical and subtropical regions, over a harvested area of approximately 10 million hectares (FAOSTAT, 2011). The annual world production accounts for about 145 million tonnes (ca. 106 million tonnes for banana and 39 million tonnes for plantain), with India as the major producer (29 million tonnes), Equador the main exporter and the European Union and United States of America the major importers of bananas (FAOSTAT, 2011). Banana plants were successfully introduced to Madeira Island (Portugal) in the middle of the 16th century and are one of the most important crops for the island's economy, representing $20 \%$ of the agricultural production and one third of the exports from the Island. Among the cultivated species, 'Dwarf Cavendish' (M. acuminata Colla var. cavendish) is by far the most important in terms of occupied area and productivity, comprising ca. $60 \%$ of the total banana production in Madeira. However, changes in the European Union banana policy prompted farmers to select and grow varieties that fulfil the needs of consumers (Council Regulation, 2006). As a response to these requirements, in addition to 'Dwarf Cavendish', new banana cultivars adapted to the edaphic 
conditions of the region have been introduced to the island (Nuno, Ribeiro, \& Silva, 1998).

The banana fruit, with an average annual per capita consumption that varies from $4.5 \mathrm{~kg}$ in USA to $16 \mathrm{~kg}$ in Sweden and up to $151 \mathrm{~kg}$ in São Tomé e Principe (Po \& Po, 2012), has a high nutritional value, contributing to an elevated intake of carbohydrates, fibre, vitamins, and minerals, together with a very low intake of fats (Arvanitoyannis \& Mavromatis, 2009; Po \& Po, 2012). In addition, banana fruits are also a rich source of phytochemicals (Po \& Po, 2012), including unsaturated fatty acids and sterols (Knapp \& Nicholas, 1969; Oliveira, Freire, Silvestre, \& Cordeiro, 2008), with a recognised role in human diets and health (Moreau, Whitaker, \& Hicks, 2002; Piironen, Lindsay, Miettinen, Toivo, \& Lampi, 2000). Our interest in ripe banana pulp results from the several studies concerning the valorisation of banana agro-industry residues, including different morphological parts of the plants (Oliveira et al., 2005), fruit peels and unripe pulp (Oliveira et al., 2008; Villaverde et al., 2013), from which several lipophilic phytochemicals with valuable nutraceutical properties, such as phytosterols, steryl glucosides, tocopherols and unsaturated fatty acids, among others, were identified.

As far as our literature survey could ascertain, no studies about the chemical composition of lipophilic extracts of ripe banana pulp of 'Chinese Cavendish', 'Giant Cavendish', 'Dwarf Red', 'Grand Nain', 'Eilon', 'Gruesa', 'Silver', 'Ricasa', 'Williams' and 'Zelig' cultivars have been published. In this vein, the present study aimed to determine the phytochemicals from several cultivars of $M$. acuminata (AAA) and M. acuminata $\times$ M. balbisiana (ABB) cultivated in Madeira Island, by assessing the lipophilic fraction chemical composition of ripe banana pulp through gas chromatography-mass spectrometry (GC-MS).

\section{Material and methods}

\subsection{Chemicals}

Dichloromethane (99\% purity), pyridine (99\% purity), trimethylchlorosilane (99\% purity), N,O-bis(trimethylsilyl)trifluoroacetamide (99\% purity), stigmasterol (95\% purity), octadecanoic acid (99\% purity), nonadecan-1-ol (99\% purity), and tetracosane $(99 \%$ purity) were supplied by Sigma-Aldrich (Madrid, Spain).

\subsection{Samples preparation}

Ten varieties of ripe bananas, namely 'Chinese Cavendish', 'Giant Cavendish', 'Dwarf Red', 'Grand Nain', 'Eilon', 'Gruesa', 'Silver', 'Ricasa', 'Williams' and 'Zelig', were kindly provided by the Bananicultura Center of the Regional Government, Lugar de Baixo, in the Madeira Island (Portugal, $32^{\circ} 40^{\prime} 47^{\prime \prime} \mathrm{N}, 17^{\circ} 5^{\prime} 13^{\prime \prime} \mathrm{W}$ ). For each variety a minimum of 50 ripe fruits were collected. Peels were separated from the fruit, and the pulps were cut, immediately frozen with liquid nitrogen, freeze dried and milled to pass through a 40-60 mesh sieve. The freeze dried samples were kept at $-18^{\circ} \mathrm{C}$ until extraction.

\subsection{Extraction}

Three powdered samples ( $20 \mathrm{~g}$ ) of each cultivar were Soxhlet extracted with dichloromethane $(600 \mathrm{~mL})$ for $6 \mathrm{~h}$. The solvent was evaporated to dryness, the lipophilic extracts were weighed and the results were expressed in percent of dry material. Dichloromethane was selected as a fairly specific solvent for lipophilic compounds isolation for analytical purposes.

\subsection{GC-MS analysis}

Before GC-MS analysis, two aliquots of each dried extract (20 mg each) and an accurate amount of internal standard (tetracosane, $0.25-0.50 \mathrm{mg}$ ) were dissolved in $250 \mu \mathrm{L}$ of pyridine. The compounds containing hydroxyl and carboxyl groups were converted into trimethylsilyl (TMS) ethers and esters, respectively, by adding $250 \mu \mathrm{L}$ of $\mathrm{N}, \mathrm{O}$-bis(trimethylsilyl)trifluoroacetamide and $50 \mu \mathrm{L}$ of trimethylchlorosilane, standing the mixture at $70{ }^{\circ} \mathrm{C}$ for 30 min (Freire, Silvestre, Neto, \& Cavaleiro, 2002). The derivatised extracts were analysed by GC-MS following previously described methods (Freire et al., 2002; Oliveira et al., 2008) on a Trace Gas Chromatograph 2000 Series, equipped with a Thermo Scientific DSQII single-quadrupole mass spectrometer and a DB-1 J\&W capillary column (30 $\mathrm{m} \times 0.32 \mathrm{~mm}$ inner diameter, $0.25 \mu \mathrm{m}$ film thickness). The chromatographic conditions were as follows: initial temperature, $80^{\circ} \mathrm{C}$ for $5 \mathrm{~min}$; temperature gradient, $4^{\circ} \mathrm{C} \mathrm{min}^{-1}$; final temperature, $260^{\circ} \mathrm{C}$; temperature gradient, $2^{\circ} \mathrm{C} \mathrm{min}^{-1}$; final

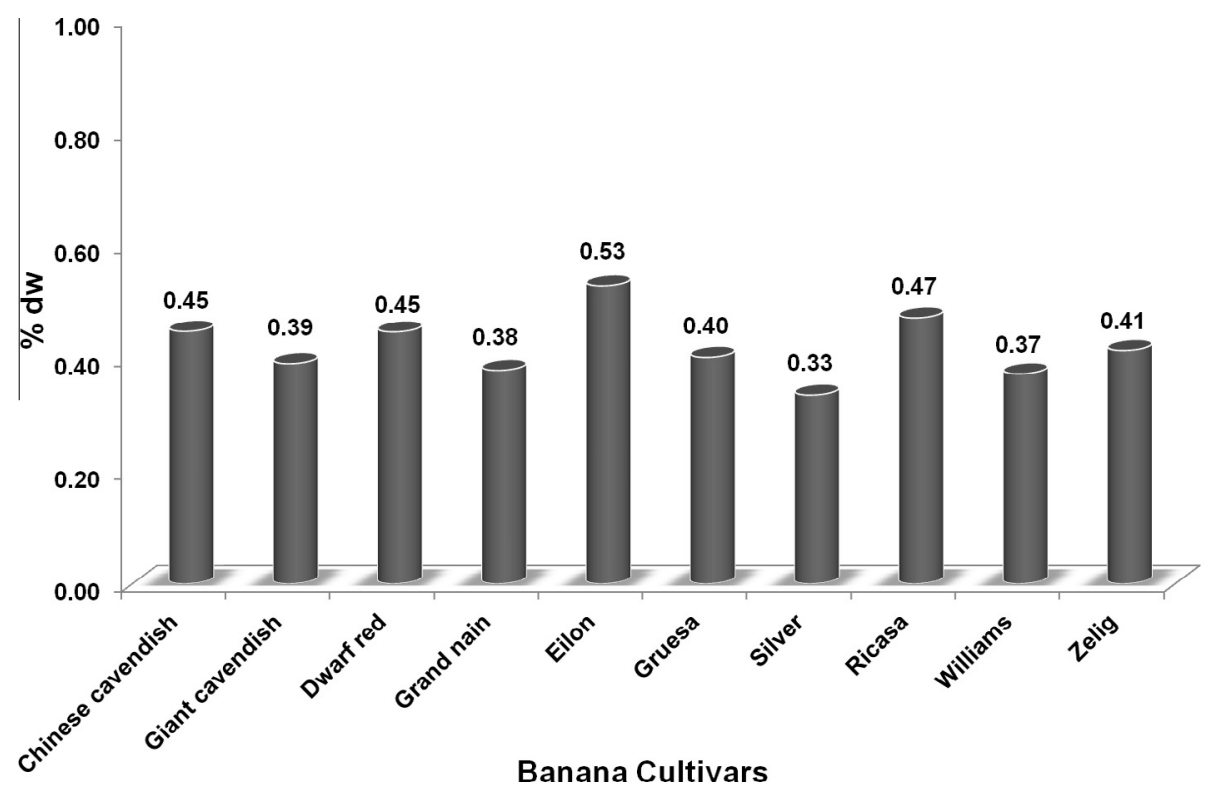

Fig. 1. Lipophilic extractive yields in dry material \% for each ripe pulp from the studied cultivars. 
temperature, $285^{\circ} \mathrm{C}$ for $8 \mathrm{~min}$; injector temperature, $250{ }^{\circ} \mathrm{C}$; transfer-line temperature, $290{ }^{\circ} \mathrm{C}$; split ratio, $1: 33$.

To check for the presence of esterified structures, samples were also analysed with a DB- $1 \mathrm{~J} \& \mathrm{~W}$ capillary column $(15 \mathrm{~m} \times 0.32 \mathrm{~mm}$ inner diameter, $0.25 \mu \mathrm{m}$ film thickness); the chromatographic conditions were as follows: initial temperature, $100^{\circ} \mathrm{C}$ for $3 \mathrm{~min}$; temperature gradient, $5^{\circ} \mathrm{C} \mathrm{min}{ }^{-1}$; final temperature, $340^{\circ} \mathrm{C}$ for $12 \mathrm{~min}$; injector temperature, $290^{\circ} \mathrm{C}$; transfer-line temperature, $290^{\circ} \mathrm{C}$; split ratio, $1: 33$.

Compounds were identified as TMS derivatives by comparing mass spectra with the GC-MS spectral library (Wiley-NIST Mass Spectral Library 1999), retention times (Oliveira et al., 2006, 2008) and fragmentation profiles with published data (Freire et al., 2002; Oliveira et al., 2005, 2006, 2008; Villaverde et al., 2009, 2013) and by injection of standards.

For semi-quantitative analysis, GC-MS was calibrated with pure reference compounds, representative of the major lipophilic extractive families (stigmasterol, octadecanoic acid and nonadecan-1-ol) relative to tetracosane. The respective response factors were calculated as an average of six GC-MS runs. The response factor of stigmasterol was used for tocopherol. Each aliquot was injected in triplicate. The results presented are the average of concordant values obtained for the six aliquots (less than $5 \%$ variation between injections of the same aliquot and between aliquots of the same banana variety extracts).

\section{Results and discussion}

Yields from the lipophilic fraction of the ripe banana pulps from the cultivars studied were markedly similar with values around $0.4 \%$ of the dry material weight, as illustrated in Fig. 1 (water contents of $70 \pm 3 \%$ were observed for these pulps upon freeze drying). The low lipidic content of these 10 cultivars is in agreement with previously published results obtained for other Musa varieties (Goldstein \& Wick, 1969; Oliveira et al., 2008), and the well-known low fat content of this fruit. Furthermore, these contents are of the same order of those found on other tropical fruits, e.g. in the ripe pulp of mango fruits (Vilela et al., 2013).

The chemical composition of extracts of the 10 banana cultivars was studied using GC-MS analysis, and the identification and quantification of the main lipophilic compounds is summarised in Table 1. In general, these extracts were composed mainly of free fatty acids (C12-C30) and sterols, followed by minor amounts of long chain aliphatic alcohols (C16-C30), among others (Fig. 2).

Table 1

Compounds identified in the lipophilic extracts of ripe pulp from banana cultivars expressed in $\mathrm{mg} \mathrm{kg}^{-1}$ of dry material.

\begin{tabular}{|c|c|c|c|c|c|c|c|c|c|c|c|}
\hline $\begin{array}{l}\text { Rt } \\
(\mathrm{min})\end{array}$ & Compound & $\begin{array}{l}\text { 'Chinese } \\
\text { Cavendish' }\end{array}$ & $\begin{array}{l}\text { 'Giant } \\
\text { Cavendish' }\end{array}$ & $\begin{array}{l}\text { 'Dwarf } \\
\text { Red' }\end{array}$ & $\begin{array}{l}\text { 'Grand } \\
\text { Nain’ }\end{array}$ & 'Eilon’ & 'Gruesa' & 'Silver’ & 'Ricasa' & 'Williams' & 'Zelig' \\
\hline & Fatty acids & 1028 & 880 & 579 & 999 & 1055 & 1284 & 939 & 774 & 1295 & 1281 \\
\hline & Saturated & 636 & 510 & 358 & 580 & 572 & 635 & 619 & 576 & 676 & 710 \\
\hline 11.67 & Dodecanoic acid & 37 & 50 & 2 & 69 & 57 & 29 & 43 & 2 & 52 & 39 \\
\hline 16.35 & Tetradecanoic acid & 20 & 26 & 9 & 24 & 24 & 15 & 24 & 6 & 23 & 21 \\
\hline 18.57 & Pentadecanoic acid & 9 & 6 & 17 & 7 & 11 & 15 & 6 & 9 & 12 & 12 \\
\hline 20.81 & Hexadecanoic acid & 396 & 251 & 245 & 269 & 256 & 402 & 276 & 257 & 378 & 456 \\
\hline 22.73 & Heptadecanoic acid & 19 & 11 & 6 & 5 & 9 & 16 & 24 & 6 & 16 & 13 \\
\hline 24.72 & Octadecanoic acid & 74 & 83 & 30 & 115 & 99 & 66 & 169 & 268 & 95 & 78 \\
\hline 26.55 & Nonadecanoic acid & 34 & 50 & 10 & 38 & 54 & 30 & 42 & 4 & 49 & 37 \\
\hline 28.36 & Eicosanoic acid & 11 & 6 & 9 & 20 & 17 & 16 & 6 & 6 & 14 & 11 \\
\hline 30.10 & Heneicosanoic acid & 5 & 4 & 4 & 3 & 4 & 3 & 3 & 1 & 3 & 6 \\
\hline 32.77 & Docosanoic acid & 7 & 6 & 7 & 15 & 16 & 11 & 6 & 4 & 15 & 10 \\
\hline 33.38 & Tricosanoic acid & 4 & 3 & 4 & 3 & 4 & 6 & 3 & 2 & 3 & 5 \\
\hline 34.94 & Tetracosanoic acid & 10 & 3 & 6 & 6 & 9 & 13 & 7 & 5 & 7 & 11 \\
\hline 36.45 & Pentacosanoic acid & 5 & 2 & 2 & 2 & 4 & 6 & 4 & 3 & 3 & 5 \\
\hline 37.92 & Hexacosanoic acid & 2 & 2 & 2 & 1 & 3 & 4 & 3 & 1 & 2 & 3 \\
\hline 39.35 & Heptacosanoic acid & 1 & 2 & 2 & 1 & 1 & 1 & 1 & 1 & 1 & n.d. \\
\hline \multirow[t]{2}{*}{43.37} & Triacontanoic acid & 2 & 5 & 3 & 2 & 4 & 2 & 2 & 1 & 3 & 3 \\
\hline & Unsaturated & 384 & 365 & 216 & 415 & 475 & 645 & 316 & 195 & 614 & 562 \\
\hline 20.13 & Hexadec-9-enoic acid & 49 & 30 & 12 & 37 & 36 & 93 & 9 & 41 & 84 & 72 \\
\hline 23.88 & Octadeca-9,12-dienoic acid & 99 & 65 & 12 & 90 & 119 & 52 & 198 & 72 & 87 & 178 \\
\hline 24.11 & $\begin{array}{l}\text { Octadeca-9,12,15-trienoic } \\
\text { acid }\end{array}$ & 165 & 215 & 125 & 237 & 263 & 405 & 36 & 62 & 350 & 214 \\
\hline \multirow[t]{2}{*}{24.20} & Octadec-9-enoic acid & 71 & 55 & 67 & 51 & 57 & 95 & 73 & 20 & 93 & 98 \\
\hline & Diacids & 6 & 1 & 2 & 1 & 2 & 3 & 1 & 1 & 4 & 5 \\
\hline \multirow[t]{2}{*}{15.36} & Nonadioic acid & 6 & 1 & 2 & 1 & 2 & 3 & 1 & 1 & 4 & 5 \\
\hline & $\omega$-Hydroxy acids & 2 & 4 & 3 & 3 & 6 & 1 & 3 & 2 & 1 & 4 \\
\hline \multirow[t]{2}{*}{37.29} & 22-Hydroxydocosanoic acid & 2 & 4 & 3 & 3 & 6 & 1 & 3 & 2 & 1 & 4 \\
\hline & $\begin{array}{l}\text { Long chain aliphatic } \\
\text { alcohols }\end{array}$ & 45 & 57 & 49 & 58 & 81 & 22 & 52 & 35 & 50 & 62 \\
\hline 18.95 & Hexadecan-1-ol & 17 & 21 & 19 & 26 & 42 & 7 & 19 & 15 & 20 & 26 \\
\hline 22.41 & (Z)-octadec-9-en-1-ol & 16 & 21 & 17 & 21 & 20 & 8 & 18 & 12 & 19 & 20 \\
\hline 23.09 & Octadecan-1-ol & 6 & 7 & 7 & 7 & 11 & 4 & 9 & 5 & 7 & 8 \\
\hline 30.39 & Docosan-1-ol & 2 & 2 & 2 & 2 & 3 & 1 & 1 & 1 & 2 & 2 \\
\hline 33.65 & Tetracosan-1-ol & n.d. & n.d. & 1 & n.d. & n.d. & n.d. & n.d. & n.d. & n.d. & n.d. \\
\hline \multirow[t]{2}{*}{39.53} & Octacosan-1-ol & 4 & 6 & 3 & 2 & 5 & 2 & 5 & 2 & 2 & 6 \\
\hline & Sterols & 155 & 263 & 176 & 233 & 296 & 275 & 182 & 316 & 237 & 169 \\
\hline 40.39 & Campesterol & 26 & 27 & 18 & 37 & 59 & 44 & 30 & 43 & 46 & 28 \\
\hline 40.86 & Stigmasterol & 23 & 46 & 26 & 30 & 49 & 43 & 29 & 43 & 37 & 26 \\
\hline 41.75 & $\beta$-Sitosterol & 105 & 186 & 130 & 163 & 185 & 184 & 121 & 226 & 152 & 113 \\
\hline 42.33 & $\begin{array}{l}\text { Cycloartenol } \\
\text { Others }\end{array}$ & 1 & 4 & 2 & 3 & 3 & 4 & 2 & 4 & 2 & 2 \\
\hline 39.15 & $\alpha$-Tocopherol & n.d. & 3 & 4 & 2 & 3 & 4 & 5 & 3 & 3 & 7 \\
\hline
\end{tabular}

n.d., Not detectable.

${ }^{a}$ Results are the average of the concordant values obtained (less than $5 \%$ variation between injections) for the two aliquots of each sample injected in triplicate. 


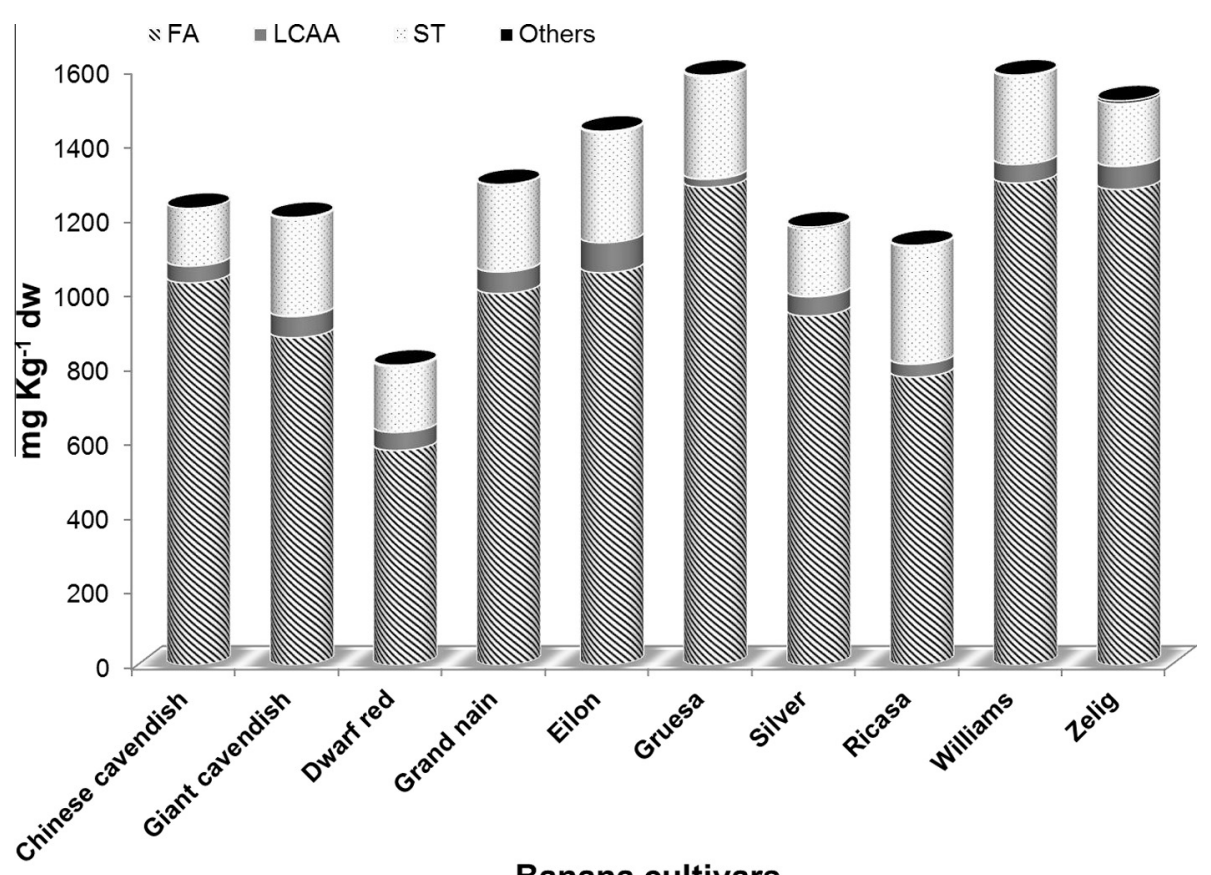

Fig. 2. Major families of lipophilic components identified in the banana pulp extracts. FA, fatty acids; LCAA, long-chain aliphatic alcohols; ST, sterols.

The relative abundance of the compounds identified and their families, differ somewhat among cultivars, as depicted in Fig. 2.

Fatty acids represented about $68.6-84.3 \%$ of the lipophilic components extracted from the selected ripe banana pulps, which is in close agreement with the value (66\%) observed for unripe pulp of 'Dwarf Cavendish' (Oliveira et al., 2008). However, the total fatty acid contents found for the ripe pulps of the 10 cultivars (579$1295 \mathrm{mg} \mathrm{kg}^{-1}$ of dry pulp) studied were considerably lower than those found for unripe pulp of 'Dwarf Cavendish' (4348 $\mathrm{mg} \mathrm{kg}^{-1}$ of dry pulp) (Oliveira et al., 2008), which was expected given the early stage of maturation of the latter (Goldstein \& Wick, 1969). The cultivars 'Williams', 'Gruesa' and 'Zelig' contained the most fatty acids $\left(1295,1284\right.$ and $1281 \mathrm{~g} \mathrm{~kg}^{-1}$ of dry material, respectively), while 'Dwarf red' contained the least $\left(579 \mathrm{mg} \mathrm{kg}^{-1}\right.$ of dry material). Saturated fatty acids, such as hexadecanoic (245$402 \mathrm{mg} \mathrm{kg}^{-1}$ of dry material) and octadecanoic (30-268 mg kg-1 of dry material) acids were the most abundant components in all cultivars, ranging from $24.3-42.3 \%$ and $5.1-34.6 \%$ of the total fatty acids content, respectively (Table 1 ). Unsaturated fatty acids were also present in high amounts, with octadeca-9,12,15-trienoic acid (an $\omega-3$ fatty acid) the major compound of this group, with the highest content observed in the cultivar 'Gruesa' $\left(405 \mathrm{mg} \mathrm{kg}^{-1}\right.$ of dry pulp) and the lower in 'Silver' ( $36 \mathrm{mg} \mathrm{kg}^{-1}$ of dry pulp), followed by octadeca-9,12-dienoic acid (an $\omega-6$ fatty acid) with $12-198 \mathrm{mg} \mathrm{kg}^{-1}$ of dry pulp. Minor amounts of nonadioic (1-6 mg kg-1 of dry pulp) and 22-hydroxy-docosanoic acids (1-6 mg kg-1 of dry pulp) were found for the first time in all ten cultivars.

Whereas saturated and monounsaturated fatty acids are not essential dietary lipids, polyunsaturated fatty acids like octadeca9,12-dienoic ( $\omega$-6) and octadeca-9,12,15-trienoic ( $\omega$-3) acids are essential nutrients that must be present in the diet since they are not synthesised in the human body (Sánchez-Moreno, De Pascual-Teresa, De Ancos, \& Cano, 2012). These banana pulps

\section{Main families: Fatty acids and Sterols}

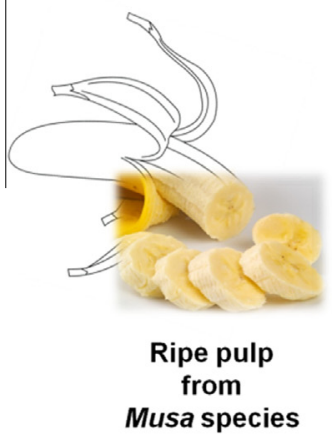

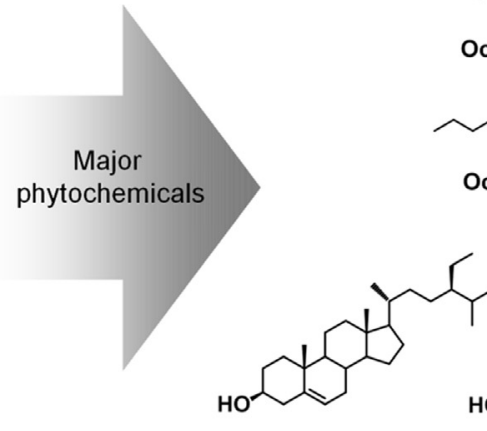

$\beta$-sitosterol

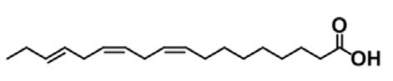

Octadeca-9,12,15-trienoic acid<smiles>CCCCCC=CC=CCCCCCCCC(=O)O</smiles>

Octadeca-9,12-dienoic acid<smiles>CCC(/C=C/[C@H](C)C1CCC2C3C=CC4CC(O)CCC4(C)C3CCC21C)C(C)C</smiles>

Campesterol

Stigmasterol

Fig. 3. Major phytochemicals identified in the banana pulp extracts. 
are a good source of $\omega-3$ and $\omega-6$ fatty acids (Fig. 3), with 'Gruesa' contributing to the highest intake of octadeca-9,12,15-trienoic acid (ca. $12.1 \mathrm{mg}$ per $100 \mathrm{~g}$ of fresh banana), and 'Silver' to the highest intake of octadeca-9,12-dienoic acid (ca. $5.9 \mathrm{mg}$ per $100 \mathrm{~g}$ of fresh banana), respectively. The role of fatty acids in the human health, especially $\omega-3$ and $\omega-6$ fatty acids, is associated with the prevention or reduced risk of chronic diseases, such as cancer, cardiovascular disease, osteoporosis and some immune disorders (e.g. Chen, McClements, \& Decker, 2013; Simopoulos, 1999; Simopoulos, 2008; Sánchez-Moreno et al., 2012).

Sterols, the second most abundant class of lipophilic compounds present in the ripe banana pulps, accounted for 155$316 \mathrm{mg} \mathrm{kg}^{-1}$ of dry material for 'Chinese Cavendish' and 'Ricasa', respectively. More specifically, $\beta$-sitosterol was identified in all the cultivars, representing, between $62.5 \%$ ('Eilon') and $73.9 \%$ ('Dwarf red') of total sterols contents and between $7.4 \%$ ('Zelig') and $20.0 \%$ ('Ricasa') of the total lipophilic components (Table 1). Other sterols included campesterol (18-59 $\mathrm{mg} \mathrm{kg}^{-1}$ of dry material) and stigmasterol (23-49 $\mathrm{mg} \mathrm{kg}^{-1}$ of dry material). Smaller amounts of cycloartenol (1-4 $\mathrm{mg} \mathrm{kg}^{-1}$ of dry material) were also identified in all ten cultivars. Interestingly, the sterol composition in these banana pulps devoid of 31-norcyclolaudenone, cycloeucalenone, cycloeucalenol and 24-methylenecycloartanol, which were previously identified in the banana pulp of other Musa species (Knapp \& Nicholas, 1969; Oliveira et al., 2008). From the sterol composition described above, it is clear that the ripe banana pulps from these cultivars could contribute to the intake of natural phytosterols (Fig. 3 ) in the human diets, and a practical and safe option for reducing plasma cholesterol among the population (Piironen et al., 2000; Quílez, García-Lorda, \& Salas-Salvadó, 2003). In general, the human intake of phytosterols varies from about 145$405 \mathrm{mg}$ per day (Sánchez-Moreno et al., 2012). Although fruits are not considered as good sources of sterols, 'Ricasa', the cultivar with the higher sterol content, would contribute to the intake of ca. $9.5 \mathrm{mg}$ of phytosterols per $100 \mathrm{~g}$ of fresh banana consumed.

Long-chain aliphatic alcohols (LCAA) were also detected in the ripe banana pulps (22-81 $\mathrm{mg} \mathrm{kg}^{-1}$ of dry material), representing only a small fraction of the total amount of lipophilic compounds, with hexadecan-1-ol and (Z)-octadec-9-en-1-ol as the most abundant fatty alcohols. The presence of this class of compounds was already reported for the pulp from 'Dwarf Cavendish' (Oliveira et al., 2008) and, of the 10 cultivars studied, only 'Gruesa' has a lower LCAA content. Reports on the role of LCAAs in human health suggest a decreased low-density lipoprotein cholesterol and increased high-density lipoprotein cholesterol following consumption (Hargrove, Greenspan, \& Hartle, 2004).

Lastly, $\alpha$-tocopherol, the most bioactive form of vitamin $\mathrm{E}$, was the only tocopherol detected in the banana pulps studied, accounting for $2-7 \mathrm{mg} \mathrm{kg}^{-1}$ of dry material, with the highest and lowest values recorded for 'Grand Nain' and 'Zelig', respectively (Table 1). Compared with previously published data, the $\alpha$-tocopherol contents were lower than in 'Dwarf Cavendish' unripe pulp (10 $\mathrm{mg} \mathrm{kg}^{-1}$ of dry pulp) (Oliveira et al., 2008), but in agreement with average values reported elsewhere (Carughi, 2013; Chun, Lee, Ye, Exler, \& Eitenmiller, 2006; Sánchez-Moreno et al., 2012). As expected, the $\alpha$-tocopherol content $(0.1 \mathrm{mg}$ per $100 \mathrm{~g}$ of fresh banana) was similar to other fruits and vegetables (Chun et al., 2006), but much less than vegetable oils, nuts and grains (Tiwari \& Cummins, 2013). Even though fruits like banana have a low content of $\alpha$-tocopherol, their consumption together with other plantderived foods provides a significant amount of vitamin $\mathrm{E}$ (Eitenmiller \& Lee, 2004), which has been associated with the prevention of cardiovascular diseases, cancer, inflammatory diseases, neurological disorders, cataract and age-related macular degeneration, as well as to the maintenance of the immune system (Bramley et al., 2000).

In order to verify the presence of esterified fatty acids (diglycerides, triglycerides and steryl esters) or steryl glucosides already reported for unripe, mature and defective banana fruits from 'Dwarf Cavendish' (Oliveira et al., 2005, 2008), the lipophilic extracts of all banana pulps were also analysed by GC-MS with a short length $(15 \mathrm{~m})$ column, using chromatographic conditions that enable the elution and detection of such low-volatile lipophilic compounds (Freire et al., 2002). Although steryl glucosides and steryl esters were found in good amounts in the unripe pulp of 'Dwarf Cavendish' (Oliveira et al., 2008), here steryl glucosides, namely campesteryl $3 \beta$-D-glucopyranose, stigmasteryl $3 \beta$-D-glucopyranoside and sitosteryl 3 $\beta$-D-glucopyranoside (41.97, 42.22 and $42.67 \mathrm{~min}$, respectively), and steryl esters were only detected in small amounts, as illustrated in Fig. 4. Even so, their presence

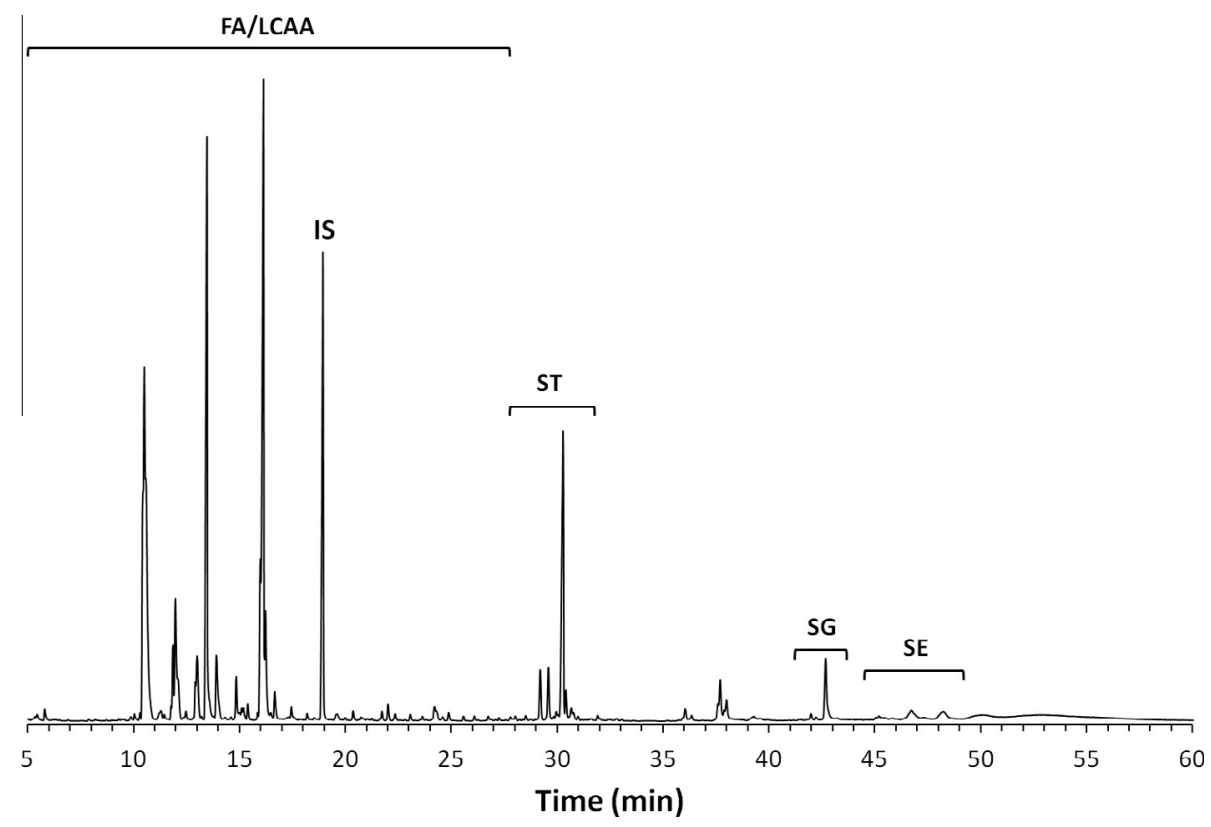

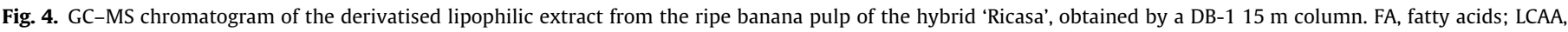
long-chain aliphatic alcohols; ST, sterols; SG, steryl glucosides; SE, steryl esters; IS, internal standard. 
together with free sterols is important to support lipid metabolism and immune function (Moreau et al., 2002).

\section{Conclusions}

The present work represents the first study on the lipophilic components from the ripe pulp of ten banana cultivars of the $M$. acuminata and M. balbisiana species, namely 'Chinese Cavendish', 'Giant Cavendish', 'Dwarf Red', 'Grand Nain', 'Eilon', 'Gruesa', 'Silver', 'Ricasa', 'Williams' and 'Zelig', cultivated in Madeira Island. The major groups of compounds identified in the lipophilic fraction of the extracts consisted mainly of fatty acids (579-1295 mg kg-1 of dry pulp) and sterols (155-316 $\mathrm{mg} \mathrm{kg}^{-1}$ of dry pulp), followed by long-chain aliphatic alcohols (22-81 $\mathrm{mg} \mathrm{kg}^{-1}$ of dry pulp). Among all the compounds identified, hexadecanoic and octadeca9,12,15-trienoic acids, and $\beta$-sitosterol were the major compounds found in all pulp samples. These data shows that the 10 cultivars investigated are a potential source of valuable phytochemicals, such as $\omega-3$ and $\omega-6$ fatty acids and sterols, with beneficial effects in human nutrition and health.

Finally, considering that unripe fruits and peels are richer in some of these bioactive compounds than mature fruits, the use of extracts from these residues would be an interesting option to prepare functional foods based on ripe banana pulp. However, to achieve that goal non-hazardous extraction systems such as supercritical $\mathrm{CO}_{2}$ need to be tested first.

\section{Acknowledgments}

The authors wish to thank the Madeira Bananicultura Center for kindly providing the samples, FCT- Portugal (Fundação para a Ciência e Tecnologia) and POPH/FSE for the postdoctoral Grants to C. Vilela (SFRH/BPD/84168/2012) and S. A. O. Santos (SFRH/BPD/ 84226/2012); for C. Freire Research Contract under the Program "Investigador FCT 2012" and for Associate Laboratory CICECO funding (PEst-C/CTM/LA0011/2013; FCOMP-01-0124-FEDER037271).

\section{References}

Arvanitoyannis, I. S., \& Mavromatis, A. (2009). Banana cultivars, cultivation practices, and physicochemical properties. Critical Reviews in Food Science and Nutrition, 49, 113-135.

Ball, T., Vrydaghs, L., Van Den Hauwe, I., Manwaring, J., \& De Langhe, E. (2006). Differentiating banana phitoliths: Wild and edible Musa acuminata and Musa balbisiana. Journal of Archaeological Science, 33, 1228-1236.

Bramley, P. M., Elmadfa, I., Kafatos, A., Kelly, F. J., Manios, Y., Roxborough, H. E., Schuch, W., Sheehy, P. J. A., \& Wagner, K.-H. (2000). Vitamin E. Journal of the Science of Food and Agriculture, 80, 913-938.

Carughi, A. (2013). Bananas, dried bananas, and banana chips: Nutritional characteristics, phytochemicals, and health effects. In C. Alasalvar \& F. Shahidi (Eds.), Dried fruits: Phytochemicals and health effects (pp. 414-427). Oxford: Blackwell Publishing Ltd..

Chen, B., McClements, D. J., \& Decker, E. A. (2013). Design of foods with bioactive lipids for improved health. Annual Review of Food Science and Technology, 4, 35-56.
Chun, J., Lee, J., Ye, L., Exler, J., \& Eitenmiller, R. R. (2006). Tocopherol and tocotrienol contents of raw and processed fruits and vegetables in the United States diet. Journal of Food Composition and Analysis, 19, 196-204.

Council Regulation (EC) No 2013/2006 (OJ No. L 384, 29.12. 2006), pp. 13-19.

Eitenmiller, R. R., \& Lee, J. (2004). Vitamin E: Food chemistry, composition and analysis. New York: Marcel Dekker.

FAOSTAT (Food and Agriculture Organization of the United Nations), 2011. URL http://faostat.fao.org/. Accessed 26.11.2013.

Freire, C. S. R., Silvestre, A. J. D., Neto, C. P., \& Cavaleiro, J. A. S. (2002). Lipophilic extractives of the inner and outer barks of Eucalyptus globulus. Holzforschung, 56, 372-379.

Goldstein, J. L., \& Wick, E. L. (1969). Lipid in ripening banana fruit. Journal of Food Science, 34, 482-484.

Hargrove, J. L., Greenspan, P., \& Hartle, D. K. (2004). Nutritional significance and metabolism of very long chain fatty alcohols and acids from dietary waxes. Experimental Biology and Medicine, 229, 215-226.

Knapp, F. F., \& Nicholas, H. J. (1969). The sterols and triterpenes of banana pulp. Journal of Food Science, 34, 584-586.

Lim, T. K. (2012). Edible medicinal and non medicinal plants: fruits (Vol. 3). New York: Springer.

Moreau, R. A., Whitaker, B. D., \& Hicks, K. B. (2002). Phytosterols, phytostanols, and their conjugates in foods: Structural diversity, quantitative analysis, and healthpromoting uses. Progress in Lipid Research, 41, 457-500.

Nuno, L., Ribeiro, V. P., \& Silva, J. (1998). Preliminary studies of Cavendish banana cultivars under the edafoclimatic conditions of Madeira Island. Acto Horticulturae (ISHS), 490, 85-88.

Oliveira, L., Freire, C. S. R., Silvestre, A. J. D., \& Cordeiro, N. (2008). Lipophilic extracts from banana fruit residues: A source of valuable phytosterols. Journal of Agricultural and Food Chemistry, 56, 9520-9524.

Oliveira, L., Freire, C. S. R., Silvestre, A. J. D., Cordeiro, N., Torres, I. C., \& Evtuguin, D. (2005). Steryl glucosides from banana plant Musa acuminate Colla var Cavendish. Industrial Crops and Products, 22, 187-192.

Oliveira, L., Freire, C. S. R., Silvestre, A. J. D., Cordeiro, N., Torres, I. C., \& Evtuguin, D. (2006). Lipophilic extractives from different morphological parts of banana plant "Dwarf Cavendish". Industrial Crops and Products, 23, 201-211.

Piironen, V., Lindsay, D. G., Miettinen, T. A., Toivo, J., \& Lampi, A.-M. (2000). Plant sterols: Biosynthesis, biological function and their importance to human nutrition. Journal of the Science of Food and Agriculture, 80, 939-966.

Po, L. O., \& Po, E. C. (2012). Tropical fruits I: Banana, mango and pineapple. In N. K. Sinha, J. S. Sidhu, J. Barta, J. S. B. Wu, \& M. P. Cano (Eds.), Handbook of fruits and fruit processing (pp. 565-589). Iowa: John Wiley \& Sons Ltd..

Quílez, J., García-Lorda, P., \& Salas-Salvadó, J. (2003). Potential uses and benefits of phytosterols in diet: Present situation and future directions. Clinical Nutrition, 22, 343-351.

Sánchez-Moreno, C., De Pascual-Teresa, S., De Ancos, B., \& Cano, M. P. (2012) Nutritional quality of fruits. In N. K. Sinha, J. S. Sidhu, J. Barta, J. S. B. Wu, \& M. P. Cano (Eds.), Handbook of fruits and fruit processing (pp. 73-84). Iowa: John Wiley \& Sons Ltd..

Sharrock, S., \& Frison, E. (1998). Musa production around the world - trends varieties and regional importance. INIBAP Annual Report, 42-47.

Simopoulos, A. P. (1999). Essential fatty acids in health and chronic disease. The American Journal of Clinical Nutrition, 70, 560s-569s.

Simopoulos, A. P. (2008). The importance of the omega-6/omega-3 fatty acid ratio in cardiovascular disease and other chronic diseases. Experimental Biology and Medicine, 233, 674-688.

Tiwari, U., \& Cummins, E. (2013). Fruit and vegetables. In B. K. Tiwari, N. P. Brunton, \& C. Brennan (Eds.), Handbook of plant food phytochemicals: Sources, stability and extraction (pp. 105-137). Oxford: John Wiley \& Sons Ltd..

Vilela, C., Santos, S. A. O., Oliveira, L., Camacho, J. F., Cordeiro, N., Freire, C. S. R., \& Silvestre, A. J. D. (2013). The ripe pulp of Mangifera indica L.: A rich source of phytosterols and other lipophilic phytochemicals. Food Research International, $54,1535-1540$

Villaverde, J. J., Domingues, R. M. A., Freire, C. S. R., Silvestre, A. J. D., Pascoal Neto, C., Ligero, P., \& Vega, A. (2009). Miscanthus $x$ giganteus extractives: A source of valuable phenolic compounds and sterols. Journal of Agricultural and Food Chemistry, 57, 3626-3631.

Villaverde, J. J., Oliveira, L., Vilela, C., Domingues, M. R. M., Freitas, N., Cordeiro, N., Freire, C. S. R., \& Silvestre, A. J. D. (2013). High valuable compounds from the unripe peel of several Musa species cultivated in Madeira Island (Portugal). Industrial Crops and Products, 42, 507-512. 